\title{
The carbohydrate-binding module of xylanase from Nonomuraea flexuosa decreases its non-productive adsorption on lignin
}

\author{
Junhua Zhang ${ }^{1 *}$, Ulla Moilanen$^{2}$, Ming Tang ${ }^{1}$ and Liisa Viikari ${ }^{2}$
}

\begin{abstract}
Background: The enzymatic hydrolysis step converting lignocellulosic materials into fermentable sugars is recognized as one of the major limiting steps in biomass-to-ethanol process due to the low efficiency of enzymes and their cost. Xylanases have been found to be important in the improvement of the hydrolysis of cellulose due to the close interaction of cellulose and xylan. In this work, the effects of carbohydrate-binding module (CBM family II) of the xylanase 11 from Nonomuraea flexuosa ( Nf Xyn11) on the adsorption and hydrolytic efficiency toward isolated xylan and lignocellulosic materials were investigated.

Results: The intact family 11 xylanase of N. flexuosa clearly adsorbed on wheat straw and lignin, following the Langmuir-type isotherm. The presence of the CBM in the xylanase increased the adsorption and hydrolytic efficiency on insoluble oat spelt xylan. But the presence of the CBM did not increase adsorption on pretreated wheat straw or isolated lignin. On the contrary, the CBM decreased the adsorption of the core protein to lignin containing substrates, indicating that the CBM of $N$. flexuosa xylanase did not contribute to the non-productive adsorption.

Conclusion: The CBM of the $N$. flexuosa xylanase was shown to be a xylan-binding module, which had low affinity on cellulose. The CBM of the N. flexuosa xylanase reduced the non-specific adsorption of the core protein to lignin and showed potential for improving the hydrolysis of lignocellulosic materials to platform sugars.
\end{abstract}

Keywords: Carbohydrate binding module, Xylanase, Adsorption, Xylan

\section{Background}

Utilization of lignocellulosic materials offers great potential to reduce our dependence on fossil fuels. The enzymatic hydrolysis step converting lignocellulosic materials into fermentable sugars is recognized as one of the major limiting steps in biomass-to-ethanol process due to the recalcitrant and complex structure of the lignocellulosic substrate and the relatively high cost of enzymes. The fermentable sugars are derived from cellulose and hemicelluloses in lignocellulosic materials. To convert cellulose into glucose, three major cellulase groups are required: endoglucanases, cellobiohydrolases and $\beta$-glucosidase, which synergistically hydrolyze cellulose [1]. Xylans, the main hemicelluloses in hardwoods and annual plants, are closely associated with the cellulose

\footnotetext{
* Correspondence: junhuazhang@nwsuaf.edu.cn

${ }^{1}$ College of Forestry, Northwest A\&F University, 3 Taicheng Road, Yangling

712100, China

Full list of author information is available at the end of the article
}

fibrils, as well as lignin, and cover the fiber surfaces [2]. After pretreatment, even low amounts of residual xylan can limit the extent and efficiency of cellulose hydrolysis by cellulases, but the limitation can be overcome by addition of xylanases that solubilize xylan in the substrates [3-5]. Thus, xylanases play an important role in efficient hydrolysis of xylan-containing lignocellulosic materials.

Xylans in annual plants consist of a linear backbone of $\beta$-(1 $\rightarrow 4)$-D-xylopyranosyl residues, substituted by $\alpha$-Larabinofuranosyl units in the positions of $2-\mathrm{O}$ and/or 3 -O, by 4-O-methyl-glucopyranosyl uronic acid in the position of 2-O, and/or by acetyl groups in 2-O and/or 3-O [6]. Furthermore, some of the arabinofuranosyl units may be esterified with ferulic or p-coumaric acids [7]. Endo-1,4-xylanases cleave the internal $\beta$-1,4-glycosyl bonds in the xylan main chain and produce xylo-oligosaccharides as main products. In the hydrolysis of lignocellulosic materials, addition of xylanases has been shown to
Ciomed Central

(c) 2013 Zhang et al.; licensee BioMed Central Ltd. This is an Open Access article distributed under the terms of the Creative Commons Attribution License (http://creativecommons.org/licenses/by/2.0), which permits unrestricted use, distribution, and reproduction in any medium, provided the original work is properly cited. 
significantly improve the performance of cellulases and to increase the cellulose conversion [8-10].

Most fungal cellulases and some hemicellulases studied so far have a complex modular architecture comprising a catalytic domain (CD) connected usually to the noncatalytic carbohydrate-binding module (CBM) via a flexible linker rich in either proline, threonine, and/or serine residues [11]. The CBMs are located either at the $\mathrm{N}$ - or C- terminal or both and are currently categorized into 64 defined families based on amino acid sequence similarities (http://www.cazy.org). Furthermore, these families have been categorized into three types based on their structure, function and ligand specificities: surface binding CBM (type A), glycan-chain binding CBM (type B) and small-sugar binding CBM (type C). Type A CBM includes members of families $1,2 \mathrm{a}, 3,5$ and 10 and are recognized to bind on insoluble, highly crystalline cellulose and/ or chitin [12].

It has been reported that CBMs play an important role in the improvement of enzymatic hydrolysis by cellulases [13-15]. Based on present data, the main contribution of the CBM to the enzymatic hydrolysis is the ability of $\mathrm{CBM}$ to target the catalytic domain to a specific substrate, thereby increasing the concentration of enzymes on the surface of the substrate. Recently, however, it has been shown that intact cellobiohydrolases and their core domains lacking CBM possess similar catalytic activity towards cellulose [16], and that cellobiohydrolases with and without CBM proceed along the cellulose chain with a similar speed [17].

The impacts of cellulose-binding modules in hemicellulases on the adsorption and hydrolysis of hemicelluloses have also been reported. Obviously, the close presence of hemicelluloses and cellulose in the substrates results in improved hydrolytic efficiency on hemicelluloses by enzymes containing a cellulose-binding module. Thus, the cellulose-binding module of Trichoderma reesei mannanase did not bind to mannan but increased the hydrolysis rate of insoluble mannan-cellulose complexes [18]. Fusion of the mannanase from Aspergillus aculeatus with a family I CBM from $A$. niger cellobiohydrolase $\mathrm{B}$ also improved the hydrolysis of $\mathrm{NaOH}$-pretreated softwood pulp [19]. The adsorption and hydrolytic activity on insoluble xylan by the xylanases A and B from Clostridium stercorarium, was found to be increased by the presence of two family 6 and one family 9 cellulose-binding modules, respectively $[20,21]$. Fusion of the family 6 CBM from $C$. stercorarium xylanase to a Bacillus halodurans xylanase also resulted to an increased adsorption on cellulose and insoluble xylan [22]. However, the effect of the actual xylan binding modules on the adsorption and solubilization of xylans has received only limited attention. The two $\mathrm{N}$-terminal family 22 CBMs from Thermotoga neapolitana xylanase A were found to bind on xylan but not on cellulose. The fusion of these CBMs with a family 10 xylanase from Bacillus halodurans increased the adsorption on insoluble xylan, and improved the hydrolytic efficiency of insoluble xylan but not of soluble xylan [23]. It has also been reported that the family $2 \mathrm{~b}$ xylan-binding domain 1 from Cellulomonas fimi xylanase D bound on xylan but not on cellulose [24] whereas the xylanase 11A from the same fungus was shown to contain two family $2 \mathrm{~b}$ CBMs binding on both cellulose and xylan. The CBM2b-1was shown to bind specifically on xylan and the CBM2b-2 on both insoluble and soluble oat spelt xylan, but exhibited also weak affinity to insoluble cellulose [25]. The family IIb CBM of xylanase from Streptomyces thermoviolaceus increased the catalytic activity of a xylanase from Thermotoga maritima on soluble xylan, but not on insoluble xylan [26].

The family 1 cellulose binding modules of Cel7A and Cel5A of $T$. reesei have been shown to be mainly responsible for the non-specific binding of the enzymes on lignins [27]. The intact T. reesei Cel7A and Cel5A enzymes were found to bind more on isolated lignins than the corresponding core domains. The $\beta$-glucosidase from $T$. reesei lacking a $\mathrm{CBM}$ was, however, found to bind strongly on lignin-rich residues but much less on Avicel and steam pretreated spruce [28]. Limited information on the adsorption properties of xylanases on different lignin containing materials is available.

The hydrolytic pattern of the core domain of the thermostable Xyn11 Nonomuraea flexuosa has been previously characterized on isolated xylans and lignocellulosic substrates [29]. Based on the C-termini amino acid sequence similarities, the xylanase Xyn11A of $N$. flexuosa contains a family II CBM [30]. In this work, the family II CBM of the Xyn11 from $N$. flexuosa was characterized with respect to its adsorption on insoluble xylan, lignin and pretreated wheat straw. The role of the CBM from $N$. flexuosa xylanase in the hydrolysis of isolated xylan was evaluated and the effect of CBM in xylanase from $N$. flexuosa on non-productive adsorption on lignin was investigated. The main objective of this work was to understand the impact of CBM from $N$. flexuosa xylanases in the total hydrolysis of lignocellulosic materials for platform sugars.

\section{Results and discussion}

\section{Purification of xylanases}

Most of the less thermostable enzymes in the preparation of the intact xylanase with the CBM (Nf xylF), expressed in the host strain $T$. reesei were removed already by the heat treatment $\left(60^{\circ} \mathrm{C}, \mathrm{pH} 6.0\right)$ for 2 hours. After the heat treatment, the protein concentration decreased from 10.0 to $2.2 \mathrm{mg} / \mathrm{ml}$. It indicated that most of the proteins of $T$. reesei in the preparation were less thermostable and were precipitated by the heat treatment. The decrease of the specific activities of $\beta$-xylosidase, $\beta$-glucosidase, 
endoglucanase and FPA indicated that most of these activities were removed (results not shown). As expected, the specific activity of xylanase was increased clearly, which also indicated that the Nf xylF xylanase was thermostable.

The proteins were further purified by ion exchange chromatography. The purity of Nf xylF was confirmed by sodium dodecyl sulfate polyacrylamide gel electrophoresis (SDS-PAGE, Figure 1). The band at approximately $82 \mathrm{kDa}$ was $\beta$-glucosidase produced by the host strain $T$. reesei. The core xylanase preparation without the CBM (Nf xylC) has been previously purified and characterized [29]. The two bands in $\mathrm{Nf} x y l C$ corresponded to the core domain and the core domain with the linker, respectively (Figure 1), as described previously $[28,29]$. The molecular weights of $\mathrm{Nf} x y l F$ and Nf xylC were 33.4 and $22.65 \mathrm{kDa}$, respectively, according to the analysis on SDS-PAGE, corresponding well to the previously analyzed values.

\section{Adsorption on xylan}

Enzyme adsorption is essential to concentrate the enzymes on the substrates in the hydrolysis of dilute substrate slurries. The adsorption of $\mathrm{Nf} x y l C$ and $\mathrm{Nf} x y l F$ on insoluble xylan was studied by incubating the enzymes with insoluble oat spelt xylan and determining the residual xylanase activities in the supernatants. As expected, strong adsorption (77\%) on insoluble oat spelt xylan was observed by Nf xylF whereas the CBM-less Nf xylC adsorbed significantly less (40\%, Figure 2). The results indicated that the CBM of the xylanase from $N$. flexuosa increased its adsorption to insoluble xylan. The results were thus in accordance with previously reported results on xylanases with cellulose or xylan binding modules [22,26].

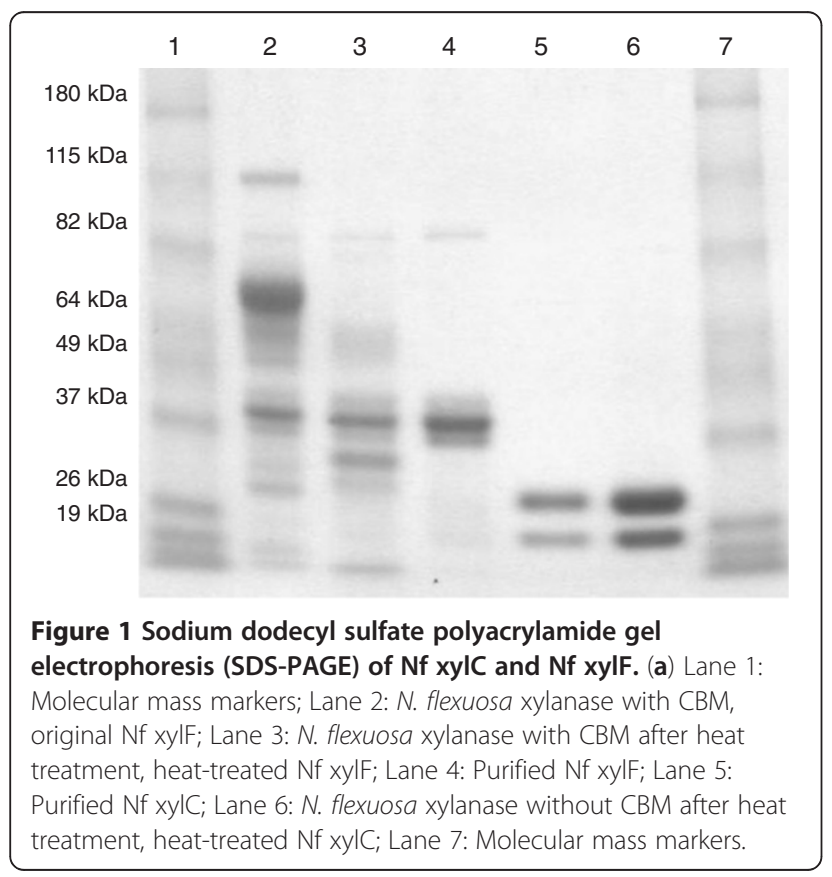

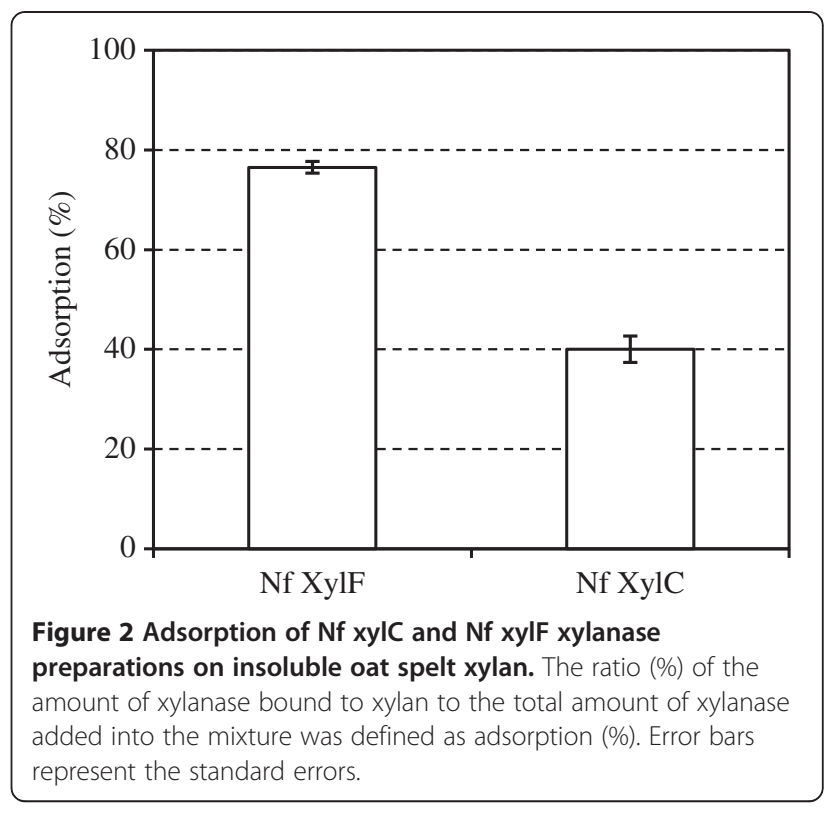

\section{Hydrolysis of isolated xylans}

In order to compare the hydrolytic activities of $\mathrm{Nf} x y l C$ and Nf xylF on soluble and insoluble xylan substrates, the enzymes were dosed on the same molar amount $(10 \mathrm{nmol} / \mathrm{g}$ dry matter (DM)). Roughly, the same amount of reducing sugars was released from the soluble oat spelt xylan (Figure 3A), indicating that $\mathrm{Nf} x y l C$ and $\mathrm{Nf} x y l F$ were equally efficient in the hydrolysis of soluble xylan and the presence of CBM did not enhance the hydrolysis of soluble oat spelt xylan. More reducing sugars were, however, released from the insoluble oat spelt xylan by Nf xylF than by Nf xylC (Figure 3B), indicating that the presence of CBM improved the hydrolytic action of the $\mathrm{Nf} x y l F$ towards insoluble xylan substrates. As previously observed, the presence of CBM obviously increased the concentration of the catalytic domain on the surface of the substrate [20,22]. As expected, a slightly lower amount of reducing sugars was released from insoluble than the soluble oat spelt xylan, especially by the Nf xylC.

\section{Adsorption on substrates}

Adsorption experiments showed that both $\mathrm{Nf} x y l C$ and $\mathrm{Nf}$ xylF had low affinity and hardly adsorbed on Avicel (Figure 4A). The CBM of Nf xylF had adsorption properties similar to the family IIb xylan-binding domain of the xylanase from C. fimi, which bound on both soluble and insoluble xylans but did not bind on cellulose [24]. The results thus suggested that the native CBM of the $\mathrm{Nf}$ xylF was truly a xylan-binding domain, obviously important in the hydrolysis of insoluble xylans.

Langmuir isotherm has been used to describe the adsorption of cellulases on cellulose, lignin or lignocellulosic materials [31-34]. The adsorption of $\mathrm{Nf} x y l C$ and 

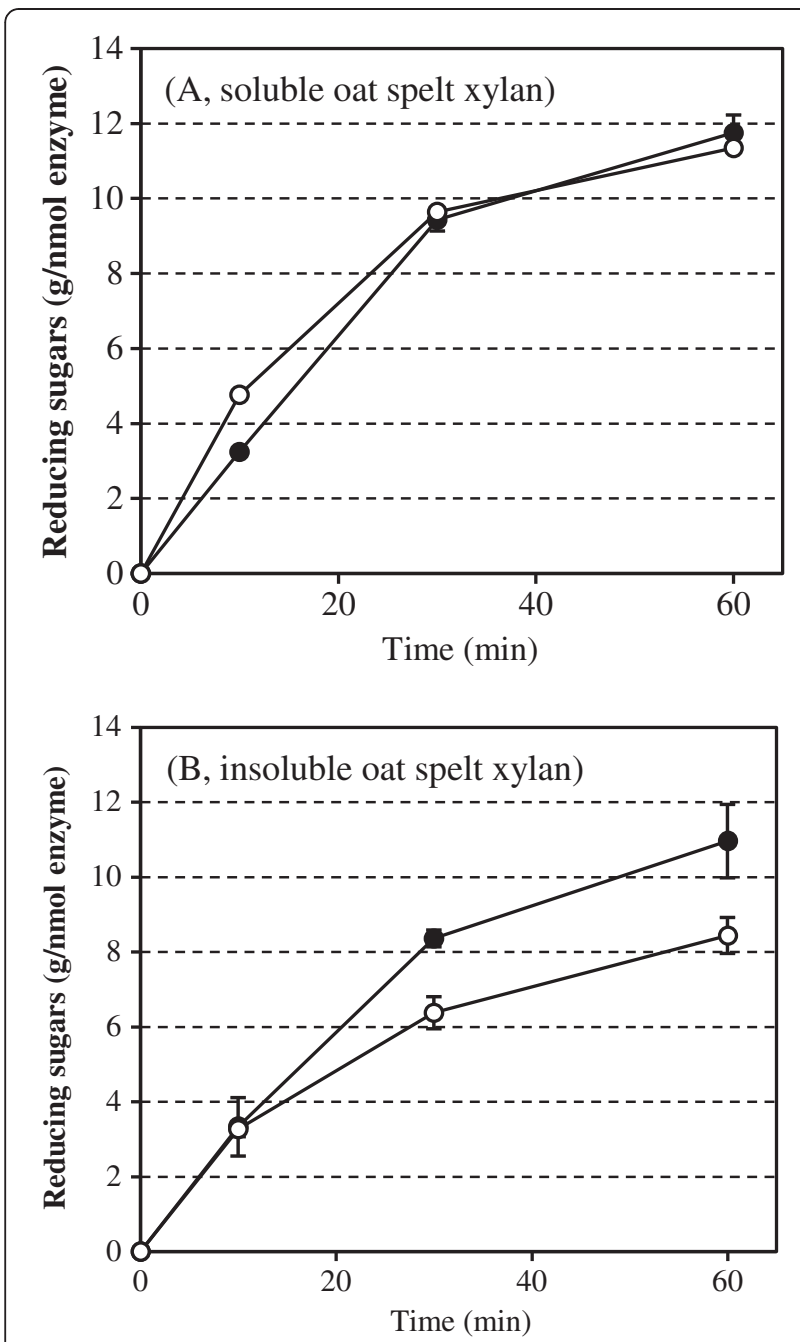

Figure 3 Hydrolysis of soluble and insoluble oat spelt xylan by Nf xyIC and Nf xylF. Soluble (A) and insoluble oat spelt xylan (B) were hydrolyzed by Nf xylC (O) and Nf xylF $(\bullet)$ xylanase preparations $(10 \mathrm{nmol} / \mathrm{g} \mathrm{DM})$ at $\mathrm{pH} 5.0$ and at $50^{\circ} \mathrm{C}$. Error bars represent the standard errors.

$\mathrm{Nf}$ xylF on lignin and wheat straw were investigated (Figure 4), and the adsorption parameters including maximum adsorption capacity $\left(P_{\text {ads, } m}\right)$, affinity constant $\left(K_{\mathrm{p}}\right)$ and strength of binding $(A)$ were calculated (Table 1). The results showed that the adsorption of $\mathrm{Nf}$ xylC and Nf xylF on lignin and wheat straw followed well the Langmuir adsorption isotherms with correlation coefficients of $\mathrm{R}^{2}>0.85$. The maximum adsorption capacities of the CBM-less Nf xylC on lignin $(135.8 \mathrm{mg} / \mathrm{g}$ substrate) and wheat straw (138.1 $\mathrm{mg} / \mathrm{g}$ substrate) were higher than those of the intact $\mathrm{Nf}$ xylF, surprisingly indicating that the $\mathrm{Nf} x y l F$ bound less on lignin than the $\mathrm{Nf}$ xylC. The maximum adsorption capacities of $\mathrm{Nf} x y l \mathrm{C}$ and $\mathrm{Nf} x y l F$ on wheat straw were about equal to those on lignin, which could be due to the high content of lignin (42.7\%) in pretreated wheat straw. The presence of CBM
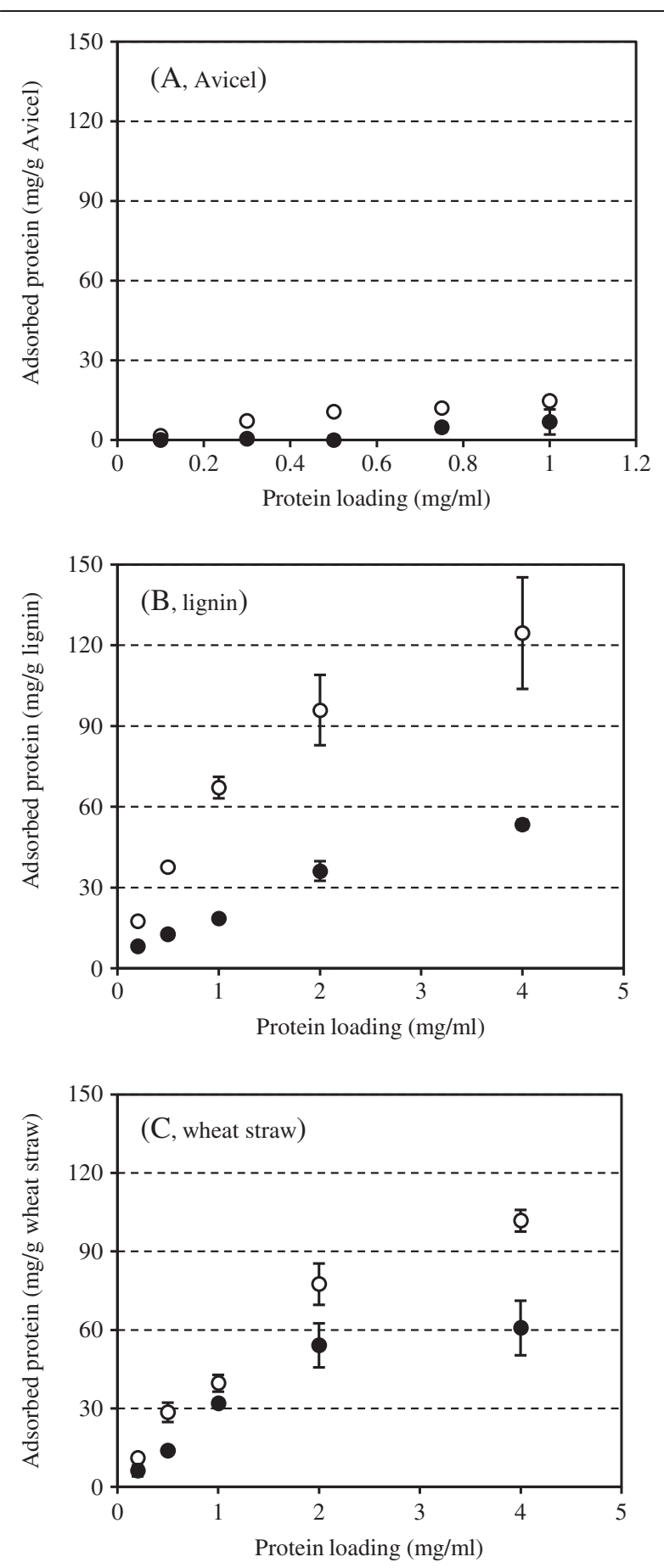

Figure 4 Adsorption of $\mathrm{Nf} x \mathrm{IC}$ and Nf xylF xylanase preparations on different substrates. A: Avicel; B: lignin; C: hydrothermally pretreated wheat straw. Adsorption experiments of $\mathrm{Nf}$ xylC (O) and Nf xylF (•) were performed at pH 5.0 and at $4^{\circ} \mathrm{C}$. Error bars represent the standard errors. 
Table 1 Adsorption parameters of Nf xylC and Nf xylF for lignin and wheat straw

\begin{tabular}{|c|c|c|c|c|c|}
\hline Solid & Enzyme & $\begin{array}{c}\text { Maximum Adsorption } \\
\text { capacity, } P_{\text {ads, } m}(\mathrm{mg} / \mathrm{g} \text { substrate) }\end{array}$ & $\begin{array}{l}\text { Affinity constants, } \\
K_{\mathrm{p}}(\mathrm{ml} / \mathrm{mg})\end{array}$ & $\begin{array}{c}\text { Strength of binding, } \\
\mathrm{R}=P_{\mathrm{ads}, \mathrm{m}} \times K_{\mathrm{p}}(\mathrm{ml} / \mathrm{g} \text { substrate) }\end{array}$ & $\mathrm{R}^{2}$ \\
\hline \multirow[t]{2}{*}{ Lignin } & $\mathrm{Nf} x y l \mathrm{C}$ & 135.8 & 3.31 & 449.50 & 0.99 \\
\hline & $\mathrm{Nf} x y \mathrm{~F}$ & 77.9 & 0.56 & 43.62 & 0.85 \\
\hline \multirow[t]{2}{*}{ Wheat straw } & $\mathrm{Nf} x y l \mathrm{C}$ & 138.1 & 0.92 & 127.05 & 0.96 \\
\hline & $\mathrm{Nf} x y \mathrm{IF}$ & 98.06 & 0.56 & 54.91 & 0.89 \\
\hline
\end{tabular}

of xylanase from $N$. flexuosa decreased the adsorption on lignin (Figure 4), resulting in the lower maximum adsorption capacities of $\mathrm{Nf} x y l F$ than those of $\mathrm{Nf} x y l \mathrm{C}$. The lower maximum adsorption capacity $(77.9 \mathrm{mg} / \mathrm{g}$ substrate) was observed for Nf xylF on lignin than on wheat straw possibly due to its relatively lower lignin content. The highest affinity constant $(3.31 \mathrm{ml} / \mathrm{mg})$ and strength of binding (449.5 ml/g substrate) were observed for the core enzyme $\mathrm{Nf} x y l C$ on lignin. The results clearly revealed that the CBM-less $\mathrm{Nf}$ xylC had higher affinity for lignin and wheat straw than the intact Nf xylF. Previously, the adsorption of xylanase on corn stover substrates obtained by different pretreatments has been investigated [33] and the maximum adsorption capacity for lime-pretreated corn stover was close to the values of $\mathrm{Nf} x y \mathrm{CC}$ for lignin and wheat straw, and that for dilute acid-pretreated corn stover was clearly lower.

The results presented here thus revealed that the xylanase from $N$. flexuosa clearly adsorbed on wheat straw and lignin non-specifically by the core domain, and the native CBM did not increase the adsorption on lignocellulosic materials or lignin. Adsorption experiments on Avicel cellulose showed that either the Nf xylC or the Nf xylF were hardly bound on Avicel, as compared to lignin and wheat straw. The results also indicated that the CBM of $N$. flexuosa xylanase did not contribute to the non-productive adsorption of the enzyme on lignin but on the contrary, the CBM of $N$. flexuosa xylanase seemed to physically prevent the strong binding of the core protein on lignin. Thus, the CBM obviously recognizes and adsorbs to the xylan substrate but seems to reduce the adsorption of the core protein to lignin.

\section{Conclusions}

The CBM of the Nf Xyn11 clearly improved the hydrolytic efficiency of the enzyme towards insoluble xylan by concentrating the enzyme on the substrate. The presence of the CBM in xylanase was, however, not shown to increase the adsorption on lignin or lignocellulosic materials. In order to improve the enzymatic conversion processes of lignocellulosic materials, use of xylanases with the CBM would thus be more beneficial than xylanases without the CBM.

\section{Methods}

\section{Substrates and chemicals}

Oat spelt xylan was obtained from Serva (Heidelberg, Germany). The lignin preparation was produced by extensive enzymatic removal of carbohydrates from thermochemically pretreated spruce followed by protease treatment to remove the bound enzymes [35]. Hydrothermally pretreated wheat straw was a kind gift of Inbicon (Fredericia, Denmark). In order to reduce the effect of dissolved sugars in the substrate, the pretreated wheat straw was washed three times by deionized water and the sugar composition was determined after acid hydrolysis by high performance liquid chromatography [36] using an analytical CarboPac PA-1 column (Dionex Corp., Sunnyvale, CA, USA), as described in the NREL procedure [37]. The washed pretreated wheat straw contained $58.9 \%$ glucan, $3.2 \%$ xylan and $42.7 \%$ lignin. D-Xylose and D-glucose (Merck, Darmstadt, Germany) were used as carbohydrate standards. All other chemicals used were of analytical grade and purchased from Sigma or Merck.

Soluble and insoluble oat spelt arabinoxylans were prepared by using a modified method of Ryan et al. [38]. Oat spelt xylan $(4 \mathrm{~g})$ was suspended in $400 \mathrm{~mL}$ of distilled water and stirred overnight at room temperature. The insoluble fraction was recovered by centrifugation at $10000 \times \mathrm{g}$ for $20 \mathrm{~min}$ and at $4^{\circ} \mathrm{C}$. The insoluble fraction was washed several times with Milli-Q water (Milli-Q Plus; Millipore, Billerica, MA, USA). After that, the sediment was lyophilized and used as insoluble oat spelt xylan for hydrolysis. The soluble fraction was lyophilized and used as soluble oat spelt xylan.

\section{Enzymes}

The xylanases with and without CBM from $N$. flexuosa were heterologously produced in a $T$. reesei strain where the genes $c b h 1$, cbh2, egl1 and egl2, encoding for cellobiohydrolase I, cellobiohydrolase II, endoglucanase I and endoglucanase II, respectively, had been deleted according to the method described elsewhere [28,39]. All these enzyme preparations were kindly provided by Roal Oy (Rajamäki, Finland).

\section{Enzyme purification}

To remove the less thermostable enzymes produced by the host strain $T$. reese $i$, the two xylanase preparations 
with and without CBM were adjusted to $\mathrm{pH} 6.0$ and were treated at $60^{\circ} \mathrm{C}$ for 2 hours. In the heat treatment, the less thermostable enzymes in the xylanase preparations were removed (Figure 1). The heat-treated xylanase preparation $\mathrm{Nf}$ xylC was desalted by ultrafiltration through an Amicon membrane with a $10 \mathrm{kDa}$ molecular mass cutoff (Amicon, USA) and purified by ion-exchange chromatography. The column with DEAE-Sepharose Fast Flow $(2.6 \times 13 \mathrm{~cm}$; Amersham Biosciences, Uppsala, Sweden) was equilibrated with $20 \mathrm{mM}$ Tris- $\mathrm{HCl}$ buffer at $\mathrm{pH}$ 8.0. Elution of bound protein from the column was accomplished by a linear gradient of $20 \mathrm{mM}$ Tris- $\mathrm{HCl}$ buffer and $20 \mathrm{mM}$ Tris- $\mathrm{HCl}$ buffer containing $0.5 \mathrm{M} \mathrm{NaCl}$. During the purification, the main peak with xylanase activity was collected for the adsorption and hydrolysis experiments. For the purification of the N. flexuosa xylanase with CBM (Nf xylF), the same method and system was used but the $\mathrm{pH}$ of buffer was adjusted to $\mathrm{pH}$ 9.1. At $\mathrm{pH}$ 8.0, the Nf xylF did not bind to the column. During the purification, two main peaks were obtained and the peak with high xylanase activity was collected for the adsorption and hydrolysis experiments. After purification by ionexchange chromatography, hydrophobic interaction chromatography with Phenyl Sepharose Fast Flow (Amersham Biosciences, Uppsala, Sweden) was applied for further purification but the band of approximately $82 \mathrm{kDa}$ could not be removed.

\section{Enzyme analysis}

Xylanase activity was assayed using $1 \%(\mathrm{w} / \mathrm{v})$ birchwood xylan (Roth 7500, Karlsruhe, Germany) as a substrate in $50 \mathrm{mM}$ sodium citrate buffer according to the method of Bailey et al. [40]. The assay was performed at pH 5.0 and $50^{\circ} \mathrm{C}$ for 5 minutes. The amount of reducing sugars liberated was determined using the dinitrosalicylic acid method with xylose used as standard [41]. One katal (1 kat) of the enzyme activity is defined as the amount of enzyme that catalyzes the release of 1 mole of reducing sugar per second. All activities presented are average values of three separate determinations.

Protein was quantified by the Lowry method, using bovine serum albumin (Sigma Chemical Co., USA) as standard [42]. SDS-PAGE was performed on $12 \%$ polyacrylamide gel using the method of Laemmli [43]. A pre-stained protein ladder (Invitrogen, Carlsbad, CA, USA) was used as a molecular weight standard. After electrophoresis, the gel was stained with Coomassie brilliant blue G-250 (Bio-Rad, Hercules, CA, USA).

\section{Adsorption experiments}

The insoluble oat spelt xylan was used for xylanase adsorption experiments. The xylanase preparations (2 $\mathrm{mg}$ protein/g DM) were incubated with $1 \%(\mathrm{w} / \mathrm{v})$ xylan at $4^{\circ} \mathrm{C}$ for $1 \mathrm{~h}$. After centrifugation the residual xylanase activity in the supernatant was measured. The amount of enzyme bound to xylan was estimated from the difference between the xylanase activities in the supernatant before and after incubation. In addition to xylan, Avicel, lignin prepared from spruce, and hydrothermally pretreated wheat straw were also used for adsorption studies. The experiments were carried out in $50 \mathrm{mM}$ sodium citric acid buffer ( $\mathrm{pH}$ 5.0) in $1 \%$ Avicel or lignin or wheat straw consistency at $1.5 \mathrm{ml}$ volume. The samples were incubated with $10-400 \mathrm{mg} / \mathrm{g}$ DM of xylanase preparation for $90 \mathrm{~min}$ at $4^{\circ} \mathrm{C}$ with magnetic stirring. After this the solids and liquids were separated by centrifugation at $4^{\circ} \mathrm{C}(10000 \times \mathrm{g}, 10 \mathrm{~min})$. The protein adsorbed was measured by subtracting the protein in supernatant from the total protein loaded. All adsorption experiments were done in triplicates and average values are presented.

\section{Calculation of adsorption parameters}

Adsorption parameters were calculated according the reported method [44,45] using the Langmuir-type adsorption isotherm as Equation below:

$$
p_{a d s}=\frac{K_{p} P_{a d s, m}}{1+K_{p} P} \cdot P
$$

where $P_{\text {ads }}$ is the amount of adsorbed enzyme ( $\mathrm{mg}$ enzyme/g substrate); $P$ is the amount of free enzyme ( $\mathrm{mg}$ enzyme/ml); $P_{\mathrm{ads}, \mathrm{m}}$ is the maximum adsorption capacity (mg enzyme/g solid); $K_{\mathrm{p}}$ is the adsorption equilibrium constant ( $\mathrm{ml} / \mathrm{mg}$ enzyme) and is a measurement for the adsorption affinity. $P_{\mathrm{ads}, \mathrm{m}}$ and $K_{\mathrm{p}}$ can be calculated from the plots of $P / P_{\text {ads }}$ vs. $P$, which gave fairly good straight lines. The adsorption strength of the enzyme $A$ is calculated from $P_{\mathrm{ads}, \mathrm{m}}$ and $K_{\mathrm{p}}\left(A=P_{\mathrm{ads}, \mathrm{m}} \times K_{\mathrm{p}}\right)$.

\section{Hydrolysis of isolated xylan}

The hydrolysis of soluble and insoluble oat spelt xylan $(2.5 \mathrm{mg} / \mathrm{mL})$ was carried out in test tubes with a working volume of $2 \mathrm{~mL}$. The enzyme dosage was $10 \mathrm{nmol} / \mathrm{g}$ $\mathrm{DM}$, based on the molecular weights of the cloned enzymes. The hydrolysis of xylan substrates was carried out in $50 \mathrm{mM}$ sodium citrate buffer at $\mathrm{pH} 5.0$ and at $50^{\circ} \mathrm{C}$. Aliquots were removed periodically at different time intervals and boiled for 10 minutes to stop the enzymatic hydrolysis. Two replicates were carried out, and average values of reducing sugars are presented.

\section{Abbreviations}

CBM: Carbohydrate binding module; CD: Catalytic domain; DM: Dry matter; $\mathrm{Nf}$ xylC: Xylanase without CBM from N. flexuosa; Nf xylF: Xylanase with CBM from N. flexuosa; SDS-PAGE: Sodium dodecyl sulfate polyacrylamide gel electrophoresis.

\section{Competing interests}

The authors declare that they have no competing interests. 


\section{Authors' contributions}

JZ carried out the experimental enzyme work, analyzed the results and drafted the manuscript. UM prepared the lignin and participated in the planning of the adsorption experiments and in the preparation of the manuscript. MT reviewed the paper. LV designed and coordinated the overall study and finalized the paper. All authors approved the final manuscript.

\section{Acknowledgements}

The authors acknowledge the financial support for this research from the $7^{\text {th }}$ FWP (HYPE project, number 213139). This work was also supported by the Natural Science Foundation of China (project number 31270622) and supported by Special Fund for Forestry Scientific Research in the Public Interest (project number 201304613). The authors are grateful to Maija Tenkanen for fruitful discussions. Roal Oy (Rajamäki, Finland) is gratefully acknowledged for providing the thermostable enzymes and Inbicon (Fredericia, Denmark) for providing the pretreated wheat straw.

\section{Author details}

${ }^{1}$ College of Forestry, Northwest A\&F University, 3 Taicheng Road, Yangling 712100, China. ${ }^{2}$ Department of Food and Environmental Sciences, University of Helsinki, P.O. Box 27, Helsinki, Finland.

Received: 11 November 2012 Accepted: 21 January 2013

Published: 30 January 2013

\section{References}

1. Nidetzky B, Kayn M, Macarron R, Steiner W: Synergism of Trichoderma reesei cellulases while degrading different celluloses. Biotechnol Lett 1993, 15:71-76.

2. Reis D, Vian B: Helicoidal pattern in secondary cell walls and possible role of xylans in their construction. Comptes Rendus Biologies 2004, 327:785-790.

3. Yang B, Wyman CE: Effect of xylan and lignin removal by batch and flowthrough pretreatment on the enzymatic digestibility of corn stover cellulose. Biotechnol Bioeng 2004, 86:88-95.

4. Öhgren K, Bura R, Saddler J, Zacchi G: Effect of hemicellulose and lignin removal on enzymatic hydrolysis of steam pretreated corn stover. Bioresour Technol 2007, 98:2503-2510.

5. García-Aparicio MP, Ballesteros M, Manzanares P, Ballesteros I, González A, Negro MJ: Xylanase contribution to the efficiency of cellulose enzymatic hydrolysis of barley straw. Appl Biochem Biotechnol 2007, 136-140:353-366.

6. Aspinall GO: Structural chemistry of the hemicelluloses. Adv Carbohydr Chem 1959, 14:429-468.

7. Mueller-Harvey I, Hartley RD, Harris PJ, Curzon EH: Linkage of $p$-coumaroyl and feruloyl groups to cell-wall polysaccharides of barley straw. Carbohydr Res 1986, 148:71-85.

8. Berlin A, Gilkes N, Kilburn D, Bura R, Markov A, Skomarovsky A, et al: Evaluation of novel fungal cellulase preparations for ability to hydrolyze softwood substrates -evidence for the role of accessory enzymes. Enzyme Microb Technol 2005, 37:175-184.

9. Kumar R, Wyman CE: Effect of xylanase supplementation of cellulase on digestion of corn stover solids prepared by leading pretreatment technologies. Bioresour Technol 2009, 100:4203-4213.

10. Zhang J, Tuomainen P, Siika-aho M, Viikari L: Comparison of the synergistic action of two thermostable xylanases from GH families 10 and 11 with thermostable cellulases in lignocellulose hydrolysis. Bioresour Technol 2011, 102:9090-9095.

11. Tomme R, Warren RAJ, Gilkes NR: Cellulose hydrolysis by bacteria and fungi. Adv Microbiol Physiol 1995, 37:1-81.

12. Boraston AB, Bolam DN, Gilbert HJ, Davies GJ: Carbohydrate-binding modules: fine-tuning polysaccharide recognition. Biochem J 2004, 382:769-781.

13. Ståhlberg J, Johansson G, Pettersson G: A new model for enzymatic hydrolysis of cellulose based on the two-domain structure of cellobiohydrolase I. Biotechnol 1991, 9:286-290.

14. Hall J, Black G, Ferreira L, Millward-Saddler S, Ali B, Hazlewood G, Gilbert G. The non-catalytic cellulose-binding domain of a novel cellulase from Pseudomonas fluorescens subsp. cellulosa is important for the efficient hydrolysis of Avicel. Biochem J 1995, 309:749-756.

15. Shoseyov O, Shani Z, Levy I: Carbohydrate-binding modules: biochemical properties and novel applications. Microbial Mol Biol Rev 2006, 70:283-295.
16. Jalak J, Väljamäe P: Mechanism of initial rapid rate retardation in cellobiohydrolase catalyzed cellulose hydrolysis. Biotechnol Bioeng 2010, 106:871-883.

17. Igarashi K, Koivula A, Wada M, Kimura S, Penttilä M, Samejima M: High speed atomic force microscopy visualizes processive movement of Trichoderma reesei cellobiohydrolase I on crystalline cellulose. J Biol Chem 2009, 284:36186-36190.

18. Hägglund P, Eriksson T, Collén A, Nerinckx W, Claeyssens M, Stålbrand H: A cellulose-binding module of the Trichoderma reesei $\beta$-mannanase Man5A increases the mannan-hydrolysis of complex substrates. J Biotechnol 2003, 101:37-48.

19. Pham TA, Berrin JG, Record E, To KA, Sigoillot JC: Hydrolysis of softwood by Aspergillus mannanase: role of a carbohydrate-binding module. J Biotechnol 2010, 148:163-170.

20. Sun JL, Sakka K, Karita S, Kimura T, Ohmiya K: Adsorption of Clostridium stercorarium xylanase $A$ to insoluble xylan and the importance of the CBMs to xylan hydrolysis. J Ferment Bioeng 1998, 85:63-68.

21. Ali MK, Hayashi H, Karita S, Goto M, Kimura T, Sakka K, Ohmiya K: Importance of the carbohydrate-binding module of Clostridium stercorarium xyn10B to xylan hydrolysis. Biosci Biotechnol Biochem 2001, 65:41-47.

22. Mangala SL, Kittur FS, Nishimoto M, Sakka K, Ohmiya K, Kitaoka M, Hayashi K: Fusion of family VI cellulose binding domains to Bacillus halodurans xylanase increases its catalytic activity and substrate-binding capacity to insoluble xylan. J Mol Catal B: Enzym 2003, 21:221-230.

23. Mamo G, Hatti-Kaul R, Mattiasson B: Fusion of carbohydrate binding modules from Thermotoga neapolitana with a family 10 xylanase from Bacillus halodurans S7. Extremopiles 2007, 11:169-177.

24. Simpson PJ, Bolam DN, Cooper A, Ciruela A, Hazlewood GP, Gilbert HJ, Williamson MP: A family llb xylan-binding domain has a similar secondary structure to a homologous family lla cellulose-binding domain but different ligand specificity. Structure 1999, 7:853-864.

25. Bolam DN, Xie H, White P, Simpson PJ, Hancock SM, Williamson MP, Gilbert $\mathrm{HJ}$ : Evidence for synergy between family $2 \mathrm{~b}$ carbohydrate binding modules in xylanase 11A. Biochem 2001, 40:2468-2477.

26. Kittur FS, Mangala SL, Rus'd AA, Kitaoka M, Tsujibo H, Hayashi K: Fusion of family $2 b$ carbohydrate-binding module increases the catalytic activity of a xylanase from Thermotoga maritime to soluble xylan. FEBS Lett 2003, 549:147-151.

27. Palonen H, Tjerneld F, Zacchi G, Tenkanen M: Adsorption of Trichoderma reesei $\mathrm{CBH}$ and $\mathrm{EGIl}$ and their catalytic domains on steam pretreated softwood and isolated lignin. J Biotechnol 2004, 107:65-72.

28. Rahikainen J, Mkander S, Marjamaa K, Tamminen T, Lappas A, Viikari L, Kruus K: Inhibition of enzymatic hydrolysis by residual lignins from softwood-study of enzyme binding and inactivation on lignin-rich surface. Biotechnol Bioeng 2011, 108:2823-2834.

29. Zhang J, Siika-aho M, Puranen T, Tang M, Tenkanen M, Viikari L: Thermostable recombinant xylanases from Nonomuraea flexuosa and Thermoascus aurantiacus show distinct properties in the hydrolysis of xylans and pretreated wheat straw. Biotechnol biofuels 2011, 4:12.

30. Leskinen S, Mäntylä A, Fagerström R, Vehmaanperä J, Lantto R, Paloheimo $M$, Suominen P: Thermostable xylanases, Xyn10A and Xyn11A, from the actinomycete Nonomuraea flexuosa: isolation of the genes and characterization of recombinant Xyn11A polypeptides produced in Trichoderma reesei. Appl Microbiol Biotechnol 2005, 67:495-505.

31. Belldman GA, Voragen GJ, Rombouts FM, Leeuwen SMF, Pilnik W: Adsorption and kinetic behavior of purified endoglucanase and exoglucanases from Trichoderma viride. Biotechnol Bioeng 1987, 30:251-257.

32. Kumar R, Wyman CE: Access of cellulase of cellulose and lignin for poplar solids produced by leading pretreatment technologies. Biotechnol Pro 2009, 25:807-819.

33. Kumar R, Wyman CE: Cellulase adsorption and relationship to features of corn stover solids produced by leading pretreatments. Biotehnol Bioeng 2009, 103:252-267.

34. Nakagame S, Chandra RP, Kadla JF, Saddler JN: Enhancing the enzymatic hydrolysis of lignocellulosic biomass by increasing the carboxylic acid content of the associated lignin. Biotechnol Bioeng 2011, 108:538-548.

35. Moilanen U, Kellock M, Galkin S, Viikari L: The laccase-catalyzed modification of lignin for enzymatic hydrolysis. Enzyme Microb Technol 2011, 49:492-498.

36. Tenkanen M, Siika-aho M: An a-glucuronidase of Schizophyllum commune acting on polymeric xylan. J Biotechnol 2000, 78:149-161. 
37. Sluiter A, Hames B, Ruiz R, Scarlata C, Sluiter J, Templeton D, Crocker D: Determination of structural carbohydrates and lignin in biomass. http://www. nrel.gov/biomass/pdfs/42618.pdf, 02/11 2012.

38. Ryan SE, Nolan K, Thompson R, Gubitz GM, Savage AV, Tuohy MG: Purification and characterisation of a new low molecular weight endoxylanase from Penicillium capsulatum. Enzyme Microbiol Technol 2003, 33:775-785

39. Suominen P, Mäntylä A, Karhunen T, Hakola S, Nevalainen H: High frequency one-step gene replacement in Trichoderma reesei: effects of deletions of individual genes. Mol Gen Genet 1993, 241:523-530.

40. Bailey MJ, Biely P, Poutanen K: Interlaboratory testing of methods for assay of xylanase activity. J Biotechnol 1992, 23:257-270.

41. Miller GL: Use of dinitrosalicylic acid reagent for determination of reducing sugars. Anal Chem 1959, 31:426-428.

42. Lowry OH, Roseborough NJ, Farr AL, Randall RJ: Protein measurement with the Folin phenol reagent. J Biol Chem 1951, 193:265-275.

43. Laemmli UK: Cleavage of structural proteins during the assembly of the head of bacteriophage T4. Nature 1970, 227:680-685.

44. Ryu K, Kim Y: Adsorption of a xylanase purified from pulpzyme $\mathrm{HC}$ onto alkali-lignin and crystalline cellulose. Biotechnol Lett 1998, 20:987-990.

45. Zilliox C, Debeire P: Hydrolysis of wheat straw by a thermostable endoxylanase: adsorption and kinetic studies. App/ Microbiol Biotechnol 1998, 22:58-63.

doi:10.1186/1754-6834-6-18

Cite this article as: Zhang et al.: The carbohydrate-binding module of xylanase from Nonomuraea flexuosa decreases its non-productive adsorption on lignin. Biotechnology for Biofuels 2013 6:18.

\section{Submit your next manuscript to BioMed Central and take full advantage of:}

- Convenient online submission

- Thorough peer review

- No space constraints or color figure charges

- Immediate publication on acceptance

- Inclusion in PubMed, CAS, Scopus and Google Scholar

- Research which is freely available for redistribution 